\title{
A teoria do etiquetamento do sistema penal e os crimes contra a ordem econômica: uma análise dos crimes de colarinho branco
}

\author{
A theory of criminal labeling system and crimes against economic order: an analysis of white- \\ collar crimes
}

\author{
Ana Paula de Oliveira Mazoni ${ }^{1}$ \\ Melina Girardi Fachin ${ }^{2}$
}

\begin{abstract}
Resumo
Trata-se de estudo acerca da seletividade do sistema penal e seu impacto na desconstrução das finalidades da ordem econômica. Para tanto, analisa a estrutura da teoria do etiquetamento penal ou labelling approach, que propugna o processo de eleição pela legislação penal (criminalização primária) e instâncias formais de controle de condutas desviantes (criminalização secundária) de pessoas com maior probabilidade de se tornarem delinquentes, em oposição àquelas, detentoras de poder político e econômico e com status social, que se encontram imunes ao poder punitivo do Estado, denominadas "criminosos de colarinho branco", e que engrossam a cifra dourada da criminalidade dos crimes econômicos.
\end{abstract}

Palavras-Chave: Etiquetamento do sistema penal. Crimes de colarinho branco. Ordem Econômica.

1 Graduada em Direito pela Universidade Estadual de Londrina (2003-2007). Especialista em Direito do Estado pela Universidade Estadual de Londrina (2008-2009), pós-graduanda em Direito Constitucional Contemporâneo pelo Instituto de Direito Constitucional e Cidadania de Londrina (2011-) e aluna especial do programa de Mestrado em Filosofia da Universidade Estadual de Londrina. Atua, principalmente, nas áreas de Direito Constitucional, Direito Administrativo, Teoria Geral do Direito e Teoria Geral do Estado. É assessora jurídica da Vara Criminal e Anexos da Comarca de Ibiporã - Paraná e docente das disciplinas de Organização dos Poderes (Direito Constitucional) e Serviços/Servidores Públicos (Direito do Trabalho Público/Direito Administrativo) da Faculdade Norte Paranaense (UNINORTE).

Doutoranda em Direito Constitucional, com ênfase em direitos humanos, pela Pontifícia Universidade Católica de São Paulo/BR (2010-andamento), sob a orientação da Prof. Dra. Flávia Piovesan. Visiting researcher da Harvard Law School (Cambridge/USA, janeiro à março de 2011). Possui mestrado em Filosofia do Direito pela Pontifícia Universidade Católica de São Paulo/BR (2008), sob a orientação da Prof. Dra. Flávia Piovesan, tendo defendido dissertação acerca dos fundamentos dos direitos humanos (Obra publicada pela ed. Renovar, 2009). Possui aperfeiçoamento em Direitos Humanos pelo Institut international des droits de Ihomme (Strasbourg/FR, 2005) e graduação em Direito pela Universidade Federal do Paraná/BR (2005). É professora de Direito Constitucional e Direitos Humanos nas Faculdades Dom Bosco e Faculdades Integradas do Brasil/UNIBRASIL (Curitiba/PR) e professora assistente voluntária de direitos humanos na Pós-Graduação Strictu Senso da PUC/PR. Autora de diversas obras e artigos na seara do Direito Constitucional, sobretudo no que toca à cena contemporânea dos Direitos Humanos e dos Direitos Fundamentais. Advogada sócia da banca Fachin Advogados Associados (Curitiba/PR, 2006). Membro integrante da coordenação do curso de Direito das Faculdades Integradas do Brasil/UNIBRASIL (Curitiba/PR, 2011). 


\begin{abstract}
The work is a study concerning the selectivity of the criminal system and its impact in the deconstruction of the economic order purposes. For that, it analyzes the structure of the criminal labelling theory or labelling approach, the advocates the process of election for the criminal legislation (primary criminalization) and formal instances of control of diverting behaviors (secondary criminalization) from people with higher probability of becoming delinquents, in opposition to those, detainers of policit and economic power with social status, they find immune to the punitive power of the State, called "criminal of white collar", and thicken the golden cipher of crime of the economic crimes.
\end{abstract}

Keywords: Labelling of the criminal system. Criminal of white collar.

\title{
1 Introdução
}

A ordem econômica, normativamente considerada, representa o arcabouço de prescrições constitucionais que visam assegurar, limitar e regular a atividade econômica em seus mais variados níveis, preceituando como sua finalidade precípua a garantia de existência digna para todos sob o sustentáculo da justiça social, através do estabelecimento e concretização de diversos princípios, organizativos e finalísticos, estabelecidos no artigo 170 da Constituição da República Federativa do Brasil de 1988.

A inclusão de preceitos dessa ordem, por parte do constituinte originário, demonstra, a decisão política em estabelecer, criteriosamente, os caminhos a serem galgados pela sociedade brasileira em prol de avanços na esfera econômica, como instrumento de concretização de outros direitos e garantias fundamentais inseridos no contexto de normatização democrática. Tais prescrições se consubstanciam, dessa maneira, em vetor compromissório, limitador e interpretativo de todo o arcabouço infraconstitucional a respeito de temas correlacionados.

Contudo, em uma sociedade capitalista e que logra, essencialmente, encartar todas as suas atividades sob o manto da quantificação do lucro e da acumulação de riquezas, mas que igualmente imprime quantidade significativa de preceitos relacionados a políticas públicas é patente a percepção de que os ditames constitucionais de ranço social devem ser equilibrados com aqueles que possibilitam conceitos de ordem liberal, até pela construção heterogênea do Texto Constitucional que refletiu, à época de sua promulgação, a também heterogenia das classes dominantes de poder político. 
Assim, a própria ordem econômica, nos termos do preceito normativo supramencionado, funda-se na valorização do trabalho humano e na livre iniciativa, e estabelece como princípios a soberania nacional, a propriedade privada, a função social da propriedade, a livre concorrência, a defesa do consumidor, a defesa do meio ambiente, a redução de desigualdades regionais e sociais, a busca do pleno emprego e o tratamento favorecido às empresas de pequeno porte, conceitos aparentemente contraditórios e que não prescindem de atuação estatal tendente à harmonização e equilíbrio.

O sistema penal que estabelece o controle de ações socialmente desviantes (delitos) também pode (e deve) ser analisado sob o vetor da ordem econômica, mormente a construção de um contexto democrático que enxerga o homem como sujeito inserto na realidade econômica e, para tanto, influenciado pela mesma.

Mas essa influência, se analisada pela Criminologia Crítica, deixa evidente a seletividade ilegítima operacionalizada pela Legislação Penal e pelos sistemas formais de controle, que reflete a própria relação social de poder, e que condiciona a população marginalizada ao papel de "clientela" do próprio sistema penal, responsável pela 'higienização' da sociedade. Assim, etiquetam-se sujeitos tipificados através de interações sociais complexas como sendo 'delinquentes' e se imunizam da aplicação, supostamente igualitária, da Lei Penal, os detentores do poder econômico e/ou político.

Busca-se com o presente estudo analisar a teoria do etiquetamento, ou labelling approach, através da criminalização primária e secundária, bem como os denominados "crimes de colarinho branco", e a consequente cifra negra da criminalidade, estabelecendo críticas a respeito da seletividade do sistema penal e suas consequências na desconstrução das finalidades propugnadas pelo constituinte originário ao tracejar os ditames da ordem econômica.

\section{0 etiquetamento do crime}

A teoria do labelling approach, ou etiquetamento, surgiu da passagem do paradigma baseado na investigação das causas da criminalidade, como dados préconstituídos e sem mobilidade, para o das condições da criminalidade, que resulta em construção que se movimenta no contexto social determinado, ou seja, o objeto da 
investigação criminológica deixa de ser etiológico-determinista (de indivíduos "anormais" que se diferenciam de indivíduos "normais") e é substituído pelo modelo dinâmico de análise da realidade criminal, como construção de interações e tipificações complexas ocorridas no seio das relações sociais.

Argüello (2005, p. 9) proclama que:

\begin{abstract}
A criminologia positivista tradicional caracteriza-se por um paradigma etiológico, pelo qual a criminalidade se torna um atributo de determinados indivíduos ('anormais'), cuja propensão a delinqüir pode ser determinada pelas suas características biológicas e psicológicas (diferenciando-os dos indivíduos 'normais'), ou pelos fatores socioambientais a que estão submetidos. Essa criminologia etiológica (individual ou socioestrutural) parte das seguintes questões, entre outras: quem é o criminoso? Por que pratica o crime? Quais fatores socioambientais influenciam nas taxas de criminalidade? Enfim, busca as causas ou os fatores da criminalidade com o objetivo de individualizar as medidas adequadas para eliminá-los, intervindo sobre o comportamento do autor. A ideologia da defesa social ainda predomina na criminologia contemporânea, embora tenha sido questionada e praticamente substituída por um outro paradigma, o do labeling approach (paradigma da reação social).
\end{abstract}

Para essa teoria, a complexa teia de relações sociais e de controle de poder se reflete na seleção das condutas a serem criminalizadas e a reação social para com cada uma delas, através de agências formais de controle, estas se caracterizando pela jurisdicionalização penal (criminalização primária) e agentes públicos inseridos na cadeia de atos processuais penais (criminalização secundária), bem como instituições informais de controle, tais como a família, a universidade, a igreja, a imprensa, entre outros.

Duas são as orientações sociológicas que dão suporte argumentativo e científico para tal etiquetamento penal: o interacionismo simbólico e a etnometodologia. Para a primeira, a realidade social apenas se constrói através de complexas interações sociais que tipificam os comportamentos, conferindo-Ihes significados que se estendem por meio da linguagem. Para a segunda, não é possível considerar a realidade como um dado concreto e acabado, sendo, ao contrário, o resultado de um processo de tipificação constante e dinâmico por parte dos indivíduos e dos grupos sociais aos quais pertencem.

Como salienta Andrade (1997, p. 213):

Se criminal é o comportamento criminalizado e se a criminalização não é mais do que um aspecto do conflito que se resolve através da instrumentalização do Direito 
e, portanto, do Estado por parte de quem é politicamente mais forte, os interesses que estão na base da formação e aplicação do direito Penal não são interesses comuns a todos os cidadãos, mas interesses dos grupos que têm o poder de influir sobre os processos de criminalização.

Conforme se observa, a teoria do labelling approach se manifesta como desenvolvimento da Criminologia Clássica, inaugurando a denominada "Criminologia Crítica", que propugna, a partir do conflito de classes e relações sociais, compreender o funcionamento da criminalização enquanto relacionados com os processos de estratificação e antagonismos estruturais.

Neste sentido, Baratta (2002, p. 86) argumenta que:

Esta direção de pesquisa parte da consideração de que não pode compreender a criminologia se não se estuda a ação do sistema penal, que a define e reage contra ela, começando pelas normas abstratas até a ação das instâncias oficiais (polícia, juízes, instituições penitenciárias que as aplicam), e que, por isso, o status social de delinquente pressupõe, necessariamente, o efeito da atividade das instâncias oficiais de controle social da delinquência, enquanto não adquire esse status aquele que, apesar de ter realizado o mesmo comportamento punível, não é alcançado, todavia, pela ação daquelas instâncias. Portanto, este não é considerado e tratado pela sociedade como 'delinquente'.

Assim, a legitimidade do sistema penal que seleciona as atitudes encartadas como criminosas e parte do pressuposto da reação social eivada pela influência dos detentores de poder político e econômico pode ser debatida sob o âmbito criminológico, a fim de constatar o caráter desigual de Sistema Penal, que condiciona e opta por gerir a criminalidade etiquetando e selecionando aqueles indivíduos que majoritariamente pertencem aos estratos sociais menos favorecidos - "possíveis" tendenciosos à prática de ações desviantes.

Para tanto, o processo de etiquetamento e seletividade do controle punitivo se consubstancia, formalmente, pela criminalização primária e secundária, que são exercidos pela função legislativa, no ínterim do processo de produção de normas jurídicas, e pelos agentes institucionalizados de controle, tais como a polícia, o Ministério Público, os juízes, entre outros, respectivamente.

Qualquer estudo criminológico acerca do labelling approach parte, necessariamente, da norma jurídica abstrata e geral, que não raras vezes deixa de ser aplicada com base no que se convencionou denominar de second-codes dos agentes 
institucionalizados e pela incapacidade do próprio texto normativo em atender legitimamente os proclames a que se destina.

Para Dias e Andrade (1997, p. 366):

\begin{abstract}
Esta atitude, relativamente à primeira das instâncias formais de controle a estudar, é paradigmática do propósito que preside a uma perspectivação interacionista de toda esta matéria: o conhecimento dos modelos de racionalidade e de resposta subjacentes à mortalidade dos casos criminais operada ao longo do corredor da delinquência. Seria já ocioso insistir, nesta altura, no enorme desfasamento que medeia entre a seleção abstracta, potencial e provisória, operada pela lei criminal, e a seleção efectiva e definitiva, feita pelas instâncias de criminalização secundária. Importa, por isso, num segundo momento, acompanhar a trajectória da law in action e da law in force, para atestar a sua (in)capacidade real de atingir os comportamentos subsumíveis nas suas previsões abstractas e de resistir às subculturas informais e aos second-codes que presidem às instâncias de criminalização secundária.
\end{abstract}

Para os supramencionados autores, os pressupostos da criminalização primária podem ser mencionados como a obviedade de criação de contingentes não catalogados de criminalidade, por situações não contidas no texto legal ou, se contidas, inócuas devido à incapacidade estatal de gerir o controle estatal para alcançar a todos os atos ditos desviantes; bem como a atuação da lei penal com a função de reestruturar e reelaborar os próprios fatos que serão processados e julgados como delitos. Ou seja, dentro da estrutura de organização da criminalização secundária, que o agente institucionalizado se decida primeiro, valoristicamente, se o sujeito posto à sua baila é ou não delinquente, para após, com seu processo mental construído, observar os fatos praticados e capitulá-los como delitos (DIAS; ANDRADE, 1997, p. 370).

Sob este vértice, tem-se que a hipótese legal de reação estatal também se consubstancia como um reflexo da realidade social vivida e pelo antagonismo das classes dominantes em face dos prováveis delinquentes inseridos em contextos de marginalização. Exatamente com base na teoria ora esboçada, e em sendo a realidade construída por meio de interações e seletividade que tipifica, etiqueta e estigma o criminoso, Barroso (2009, p.92) evidencia que:

No sistema capitalista de hoje, é fácil perceber que quem vai realmente preso, ou seja, aquele que sofre com o cárcere é o não-consumidor, o pobre, o negro, o desempregado, etc., enfim, todos aqueles esquecidos pela sociedade, pois é mais 
barato para o Estado prender do que fazer uma política de reintegração social. Estão rotulados pela comunidade, tanto que nunca foram presos e torturados tantos negros e pobres como hoje em dia.

Complementado por Dias e Andrade (1997, p. 385) nos seguintes moldes;

A criminologia radical sustenta, por seu turno, que a seleção não pode encarar-se em termos tão neutros. Segundo ela, a seleção operada pelas instâncias de controlo não reflecte apenas a dissonância organizacional daquelas instâncias, antes reproduz, no plano da justiça criminal, as linhas de fractura e de conflito que, a nível macroscópico, dominam cada formação social.

De outro modo, a criminalização secundária se opera através da atuação da polícia, dos membros do Ministério Público, dos magistrados, e todos os agentes públicos que participam do procedimento de persecução penal em alguma de suas fases (como peritos, psicólogos, assistentes sociais, entre outros). Ocorre o etiquetamento, nessa vertente de criminalização, por meio de posturas desiguais, burocratizadas e estigmatizantes, reduzindo a capacidade de ação e de comunicação do suposto delinquente no ínterim do processo criminal.

Dessa maneira, reproduzem-se os impasses e conflitos sociais quando, por ocasião da investigação policial, parte-se do pressuposto de que o investigado é culpado, tornandose desnecessária a arguição e procura de elementos que comprovem a versão não culpável por ele verbalizada. Além disso, no contexto institucional, a posição antidemocrática e impiedosa com a qual se raciona a localização do réu na sala de audiência, desprestigiando não sua participação e consecução de direitos, mas também inviabilizando, completamente, sua comunicação nos atos que definiram todo seu futuro, estigmatizante e inevitável.

Neste sentido, Andrade (1997, p. 270) explicita a maneira como o Direito Penal se mostra seletivo, mormente como as atribuições de estamento social influenciam na criminalização primária e secundária, a partir da tipificação e interações sociais que refletem o etiquetamento de criminosos:

Foi assim que a descoberta deste código social extralegal conduziu a uma explicação da regularidade da seleção (e das cifras negras) superadora da etiologia: da tendência a delinquir às maiores 'chances' (tendência) de ser criminalizado. A clientela do sistema penal é constituída de pobres, não porque tenham maior tendência para delinquir, mas precisamente porque têm maiores chances de serem criminalizados e etiquetados como 
delinquentes. As possibilidades (chances) de resultar etiquetado, com as graves consequências que isto implica, se encontram desigualmente distribuídas.

Ou seja, não se trata de selecionar aqueles com maiores chances, etiologicamente, de cometer infrações penais, mas sim de, preliminarmente (e com base no controle social que integra as relações de poder) selecionar a classe de pessoas que possuem mais chances de serem criminalizadas através das instâncias de controle de condutas desviantes, de maneira desigual e invariavelmente cíclica.

E enquanto as classes menos favorecidas economicamente e sem possuir status social e capacidade de influir em decisões políticas se mostram incapacitadas de se verem livres desse círculo vicioso e que se retroalimenta de criminalidade e delinquência (e se defende a posição de que a criminalidade se mostra, muitas vezes, como resposta social à situação de miséria e de ausência completa de recursos) - tendo a privação de liberdade como ápice da degradação e inviabilidade de reinserção social, tornando inconcretas as previsões constitucionais a respeito das finalidades da Ordem Econômica (artigo 170 do Texto Constitucional) - uma classe imune ao controle social de ações desviantes continua perpetrando delitos que causam sérios prejuízos patrimoniais, sem serem incomodadas.

\section{A cifra dourada da criminalidade: o crime de colarinho branco}

Denominam-se crimes de colarinho branco aqueles delitos perpetrados por pessoas que integram os chamados segmentos de pressão social, ou seja, detentoras de poder econômico e (ou) político com capacidade de influir na decisão de política criminal e nas instâncias formais e informais de controle de condutas desviantes (criminalização primária e secundária).

O termo White collar crime foi empregado pela primeira vez no ano de 1940 , e a esse respeito, orienta Andrade (1997, p. 261):

\footnotetext{
Já em seu clássico artigo White-Collar Criminality, Sutherland (1940) mostrava, com apoio de dados extraídos das estatísticas de vários órgãos americanos competentes em matéria de econômica e comércio, a impressionante proporção de infrações a normais gerais praticadas neste setor por pessoas colocadas em posição de alto prestígio social, bem como analisava as causas do fenômeno, sua ligação funcional com a estrutura social e os fatores que explicavam a sua impunidade. Posteriormente, em um artigo sugestivo intitulado Is 'White-Collar Crime' Crime?, Sutherland (1945), mostrando uma visão mais sofisticada da criminalidade do que a
} 
do paradigma etiológico - que antecipava até a visão do labelling - indagava precisamente se, devido àquela impunidade, eram crimes, os crimes de colarinho branco. [...] Por outro lado as proporções da criminalidade de colarinho branco, ilustradas por Sutherland e que remontavam os decênios precedentes, provavelmente aumentaram desde que ele escreveu seu artigo. Elas correspondem a um fenômeno criminoso característico não só dos Estados Unidos da América do Norte, mas de todas as sociedades.

Como visto, o crime de colarinho branco se consubstancia por ações delitivas, normalmente levadas a efeitos sem violência física e estrutural (nos moldes dos demais delitos), tendo como agentes pessoas que gozam de prestígio social e influência política. Ora, se o mesmo grupo, com base na teoria do etiquetamento (labelling approach), também tem o condão de influir no processo de criminalização primária e nas demais instâncias de controle de condutas desviantes, nota-se que suas próprias condutas delitivas se mostram "imunes" à ação controladora do Estado, a uma pela dificuldade de investigação e comprovação de delitos de ordem econômica ou financeira, e a duas pela reação social que, através do controle, é dirigida a punição de outros crimes, normalmente perpetrados pelas classes ditas subalternas e, portanto, tipificadas pelas interações sociais como "merecedoras" de controle penal.

De outro modo, se é verdade que as estatísticas penais, seletivamente, são falhas e não demonstram os reais contingentes criminais, pressupostos pela Criminologia Clássica, inclusive, então também é válida a premissa de que a "cifra dourada da criminalidade", consubstanciada por delitos de colarinho branco, que integram a denominada "cifra negra" do mesmo contingente, tendo em vista que a grande maioria das ações desviantes nesse modelo de conduta que não são sequer investigadas quanto mais punidas pelos agentes institucionalizados do poder penal.

Fernandes e Fernandes (2002, p. 386-387), ao analisar os fatores sociais de criminalidade e os crimes de colarinho branco, preceitua:

Mas, para a eclosão do delito, também contribuem outras camadas do estamento social, situadas na esfera dos socialmente mais desenvolvidos. Deixadas de lado as disputas casuais e as rivalidades ou rixas existem delitos que são próprios ou particulares de certas classes sociais endinheiradas, como, por exemplo, as infrações à lei sobre determinados impostos, as infrações contra o regime de sociedades anônimas, as falências fraudulentas, as concordatas, os delitos de usura, os delitos cometidos através de irregularidades em papéis, escrituração ou documentos de crédito contra o governo, etc. Esses tipos de delitos correspondem 
às cifras douradas da criminalidade, também chamados de 'crimes de colarinho branco' (White colar crime), ou seja, aqueles cujos criminosos possuem poder político, econômico ou social e que, por isso, suas atuações criminosas, na absoluta maioria dos casos, permanecem impunes, quase que representando uma condição de inimputabilidade situativa ou situacional.

Como visto, os crimes que pressupõem a ação delitiva de colarinho branco, realizados mediante instrumentos funcionais (empresariais ou não) e econômicos, normalmente se consubstanciam em fraudes contra o Poder Público, sonegação de tributos, fraude contra credores, retenção de valores devidos aos empregados, infrações à lei de usura e práticas concorrenciais abusivas, entre outros, que geram infindáveis danos à sociedade e atingem, direta ou indiretamente, bens jurídicos de grande relevância.

Assim, não obstante a seleção de delitos contra o patrimônio, efetuados pela classe fragilizada economicamente (como o furto e o roubo, por exemplo, encartados nos artigos 155 e 157 do Código Penal, respectivamente), é possível depreender que os maiores prejuízos financeiros se encontram nos crimes de colarinho branco, sendo certo que quando equiparados, tal criminalidade (sua parcela investigada e punida, ainda que mínima) supera, e muito, os demais setores de criminalização.

A propósito, ao analisar a diferenciação entre os crimes praticados pela classe operária e burguesa, em manifesta desigualdade proposta pelo sistema penal, SANTOS (1981, p. 51-52) registra que:

Na formação do capitalismo, a criminalidade é reestruturada (a nível de prática criminal, de definição legal e de repressão penal) pela posição de classe do autor: as massas populares (especialmente lumpens), circunscritas à criminalidade patrimonial, são submetidas a tribunais ordinários e a castigos rigorosos; a burguesia, circulando nos espaços da lei (silêncios, omissões e tolerâncias), movese no mundo protegido da 'ilegalidade dos direitos' (fraudes, evasões fiscais, comércio irregular, etc., na gênese histórica da criminalidade de 'colarinho branco'), com os privilégios de tribunais especiais, multas e transações, que fazem dessa criminalidade um investimento lucrativo. O sistema penal é erigido para 'gerir diferencialmente' a criminalidade (conforme sua origem social), mas sem suprimi-la. A nova 'tecnologia do poder' desloca o direito de punir da vingança do soberano para a 'defesa social' (entendida como 'defesa das condições' materiais e ideológicas da sociedade capitalista), com base na teoria do contrato social: a condição de membro do corpo social implica aceitação das normais sociais, e sua violação, a aceitação da punição.

E ainda, Martini (2007, p. 45-46) informa: 
A nossa legislação ordinária e especial é rica em demonstrações de seletividade da norma penal. À guisa de exemplo, tem-se a disparidade entre as penas previstas para os crimes contra o patrimônio público e privado. O crime de roubo é punido muito mais severamente do que o de sonegação fiscal, levando à conclusão de que, para o conjunto a sociedade brasileira, subtrair uma carteira mediante grave ameaça é mais gravoso do que sonegar milhões em impostos, ainda que o roubo de carteira apresente à vítima somente prejuízos materiais, enquanto a sonegação pode ceifar inúmeras vidas, por subtrair recursos que seriam aplicados em políticas públicas.

Baratta (2002, p.198) explicita que a grande maioria dos delitos (investigados e punidos a par da cifra dourada e, portanto, negra, da criminalidade) é de origem patrimonial, podendo ser entendida como resposta individual às mazelas sofridas pela classe subalterna, sob a forma de demonstração notória das contradições típicas de um sistema falho de distribuição de riquezas e de gratificações sociais. E ainda ressalta que:

\begin{abstract}
Vimos como isto não quer dizer, de modo algum, que o desvio criminal se concentre, efetivamente, na classe proletária e nos delitos contra a propriedade. A mesma criminologia liberal, com as pesquisas sobre a cifra negra, sobre a criminalidade do colarinho branco e sobre a criminalidade política demonstra, ao contrário, que o comportamento criminoso se distribui por todos os grupos sociais, que a nocividade social das formas de criminalidade próprias das classes dominantes e, portanto, amplamente imunes, é muito mais grave do que a de toda a criminalidade realmente perseguida. Por outro lado, o sistema das imunidades e da criminalização seletiva incide em medida correspondente sobre o estado das relações de poder entre as classes, de modo a oferecer um salvo-conduto mais ou menos amplo para as práticas ilegais de grupos dominantes, no ataque aos interesses e aos direitos das classes subalternas, ou de nações mais fracas; além disso incide, em razão inversamente proporcional à força e ao poder de controle político alcançado pelas classes subalternas, no interior das relações concretas de hegemonia, com uma mais ou menos rigorosa restrição de ações políticas dos movimentos de emancipação social.
\end{abstract}

\title{
4 A desconstrução das finalidades da ordem econômica
}

Analisando, atentamente, a teoria da seletividade e etiquetamento, ou labelling approach, bem como as características fundamentais dos crimes de colarinho branco, é imperioso que se reconheçam suas correlações com as finalidades da ordem econômica.

Preceitua o artigo 3 da Constituição Federal que:

Artigo 3ㅇ, CF: Constituem objetivos fundamentais da República Federativa do Brasil: I - construir uma sociedade livre, justa e solidária. II - garantir o desenvolvimento nacional. III - erradicar a pobreza e a marginalização e reduzir as 
desigualdades sociais e regionais. IV - promover o bem de todos, sem preconceitos de origem, raça, sexo, cor, idade e quaisquer outras formas de discriminação.

Válido ressaltar a prescrição normativa prevista pelo artigo 170 da referida Carta Constitucional:

Artigo 170, CF: A ordem econômica, fundada na valorização do trabalho humano e na livre iniciativa, tem por fim assegurar a todos existência digna, conforme os ditames da justiça social, observados os seguintes princípios: I - soberania nacional. II - propriedade privada. III - função social da propriedade. IV - livre concorrência. V - defesa do consumidor. VI - defesa do meio ambiente, inclusive mediante tratamento diferenciado conforme o impacto ambiental dos produtos e serviços e de seus processos de elaboração e prestação. VII - redução das desigualdades regionais e sociais. VIII - busca do pleno emprego. IX - tratamento favorecido para as empresas de pequeno porte constituídas sob as leis brasileiras e que tenham sua sede e administração no País.

Conforme se observa, o constituinte originário estabeleceu como objetivos da República promover o bem de todos, sem distinção de qualquer natureza, elencando como finalidade da Ordem Econômica assegurar a todos existência digna, sob o sustentáculo da justiça social.

Analisando atentamente ambos os preceitos legais, que ganham concretude através de leis infraconstitucionais e microssistemas de proteção de grupos sociais em situação de risco, e, mormente sua relação com o Direito Penal, é notória a interferência das esferas de controle de ações desviantes no contexto de efetivação dos princípios e das finalidades da Ordem Econômica, considerando suas características de fundamentalidade.

Conforme salienta Borges (2003, p. 217):

A partir do momento em que há o advento do constitucionalismo social, mudanças no modelo textual de Constituição são sentidos com a inserção dos Direitos Econômicos e Sociais. Mais do que o sistema esquemático de distribuição de textos, a valorização ideológica de uma nova dimensão constitucional, de marca reformadora, faz incluir a dimensão de normas de política econômica no texto da Constituição. [...] Inserir no texto de uma Constituição uma parte de Ordem Econômica demonstra uma opção - valorativa e ideológica - por certo modelo de tratamento da política econômica, pela presença de princípios programáticos, direitos fundamentais econômicos e a organização da ação estatal na economia em representação gráfica na Constituição. 
Dentre os "microssistemas legais" supramencionados que possibilitam, em tese, a busca por concretizar dos preceitos supramencionados é possível citar a Lei no. 8.429/92 (dispõe sobre as sanções aplicáveis aos agentes públicos no caso de enriquecimento ilícito no exercício do mandato, cargo, emprego ou função na administrativa pública direta, indireta ou fundacional), Lei no. 7.492/1986 (define os crimes contra o sistema financeiro nacional), Lei no. 11.101/2005 (define os crimes falimentares) e Lei n‥ 9.605/1998 (define os crimes contra o meio ambiente).

Ocorre, porém, que a criação e aplicação legislativa dos textos acima prescritos se encontram eivados pelas determinações de controle, conforme as interações sociais complexas, transcritas através da análise crítica do sistema penal, restando muitas vezes inaplicáveis ante a "imunidade situacional" dos detentores de pode econômico e político ou criminosos de colarinho branco.

Muitos são os desafios constitucionais com a inserção da Ordem Econômica, textualmente, na Carta Constitucional, o que passa, invariavelmente, pela delimitação de um Direito Penal não seletivo e aplicado a partir de um contexto criminológico crítico. A solução para a concretização das garantias constitucionalmente previstas, para Borges (2003, p. 232), seria:

\footnotetext{
Como transformar o modelo de Estado Empresário em bem-sucedido modelo de bem-estar? Demonstra-se, portanto, que a direção programática da Constituição deveria apontar para a solução da dimensão dos Direitos Fundamentais sociais, de uma política econômica que garantisse o acesso aos bens de consumo social, que superasse a clivagem social acentuada e o problema da fruição de Direitos sociais e econômicos, enquanto satisfação de necessidades individuais e não apenas do plano organizacional empresarial do Estado.
}

Como visto, somente com a efetividade dos direitos e garantias constitucionais, sob a ótica dos direitos fundamentais (o que é perpassado pelo direito penal não seletivo e sem etiquetamento, ao mesmo tempo em que viabilize a punição adequada da "cifra dourada" da criminalidade), garantem-se como consequência as finalidades pressupostas pela República Federativa do Brasil (artigo 3o, CF), incluindo sua Ordem Econômica (artigo 170, $\mathrm{CF})$. 


\section{Conclusão}

Após a análise das teorias do etiquetamento ou labelling approach e da seletividade do sistema penal, sendo certo que sua inobservância acarreta a desconstrução das finalidades precipitadas pela Ordem Econômica, conforme o artigo 170 da atual Carta Magna, imperioso que se reflita sobre as possibilidades de se integrar ao Direito Penal estratégias de políticas-criminais que possibilitem, criticamente, a construção de novas formas de criminalização.

Para Baratta (2002, p. 200), existem estratégias que podem ser utilizadas pelo Estado para a consecução da criticidade supramencionada. Primeiramente, partindo de uma interpretação diferenciada para a criminalidade levada a efeito pelas classes menos favorecidas e pelas classes dominantes de poder econômico e político, esta consubstanciada pelos crimes de colarinho branco, que, como visto, pressupõem um arcabouço de prejuízo social infinitamente superior aos demais delitos.

Se a criminalização primária reflete a dominação das classes mais favorecidas, e a criminalização secundária tipifica e estigmatiza sem qualquer criticidade, faz-se mister que o próprio processo penal, através de política-criminal includente, posicione-se sob a ótica das classes subalternas, aproximando a conduta desviante do patamar de tipificação penal real.

Igualmente, cabe ao Estado instrumentalizar o sistema penal a fim de que alcance os agentes "imunes" aos regramentos criminológicos, tais como os criminosos de colarinho branco, por meio de mecanismos de reação institucional que primem, cada vez mais, pelo favorecimento dos interesses coletivos (seja através da revisão legislativa, despenalização de instâncias criminais que não atingem a bem jurídicos relevantes, seja pela modificação do aparato judicial para sofisticar a investigação e repressão de organizações criminosas), maculados pelos grandes prejuízos causados pelos crimes econômicos, ou que causem enriquecimento ilícito.

Segundo o mesmo autor:

É esta a alternativa colocada em face do mito burguês da reeducação e da reinserção do condenado. Se, de fato, os desvios criminosos de indivíduos pertencentes às classes subalternas podem ser interpretados, não raramente, como uma resposta individual, e por isso não 'política' às condições sociais impostas pelas relações de produção e de distribuição capitalistas, a verdadeira 'reeducação' do condenado é a que transforma uma reação individual e egoísta em consciência e ação política dentro do movimento de classe. 
Somente através da conscientização crítica das funcionalidades reais do sistema penal, com o diagnóstico de suas operacionalidades obscuras e controladoras, é que se possibilitará, com a clareza compromissória do Texto Constitucional, aferir-se da Ordem Econômica e suas ações desviantes concernentes a finalidade necessária de se assegurar o bem de todos sob o sustentáculo da justiça social, que perpassa as relações de poder e influencia a criminalização.

\section{Referências}

ANDRADE, Vera Regina Pereira de. A ilusão de Segurança Jurídica: do controle da violência à violência do controle penal. 1. ed. Porto Alegre: Livraria do Advogado Editora, 1997.

ARGUELLO, Katie. Do Estado social ao Estado penal: invertendo o discurso da ordem. Disponível em: http://www.cirino.com.br/artigos/Artigo\%20Katie.pdf. Acesso em: 09 out. 2011.

BARATTA, Alessandro. Criminologia crítica e crítica ao direito penal: introdução à sociologia do direito penal. 3. ed. Rio de Janeiro: Editora Revan: Instituto Carioca de Criminologia, 2002.

BARROSO, Daniel Viegas S. Criminologia: Do Estado de Polícia ao Estado de Direito. Florianópolis: Conceito Editora, 2009.

BORGES, Alexandre Walmott. Preâmbulo da Constituição \& a Ordem Econômica. 1. ed. Curitiba: Juruá Editora, 2004.

DIAS, Jorge de Figueiredo; ANDRADE, Manuel da Costa. Criminologia: o Homem delinquente e a sociedade criminógena. 2. ed. Lisboa: Coimbra Editora, 1997.

ELBERT, Carlos Alberto. Criminologia latino-americana. São Paulo: LTr, 2002.

FERNANDES, Newton. FERNANDES, Valter. Criminologia Integrada. 2. ed. São Paulo: Editora Revista dos Tribunais, 2002.

GOMES, Luiz Flávio. CERVINI, Raúl. Crime Organizado: enfoque criminológico, jurídico (Lei no. 9.034/95) e político-criminal. 2. ed. São Paulo: Editora Revista dos 1997. 
A Teoria do etiquetamento do sistema penal e os crimes contra a ordem econômica: uma análise dos crimes de colarinho branco

MARTINI, Márcia. A seletividade punitiva como instrumento de controle das classes perigosas. Disponível em:

<http://aplicacao.mp.mg.gov.br/xmlui/bitstream/handle/123456789/650/3.4.1\%20A\%20sel etividade\%20punitiva.pdf? sequence=1>. Acesso em: 09 out. 2011.

MOLINA, Antônio García-Pablos. GOMES, Luiz Flávio. Criminologia. 4. ed. São Paulo: Editora Revista dos Tribunais, 2002.

SANTOS, Juarez Cirino dos. A criminologia radical. Rio de Janeiro: Editora Forense, 1981.

Artigo recebido em 17/10/2011 e aprovado para publicação em 12/03/2012. 